\title{
Stability and bone loss around submerged and non-submerged implants in diabetic and non-diabetic patients: a 7-year follow-up
}

\section{Saeed AL ZAHRANI(a) \\ Abdullah Abdulaziz AL MUTAIRI(b)}

(a) Ministry of National Guard Health Affairs, Division of Prosthodontics, Department of Dental Services, Riyadh, Saudi Arabia.

(b)Ministry of National Guard Health Affairs, Division of Advanced Education in General Dentistry, Department of Dental Services, Riyadh, Saudi Arabia.

Declaration of Interests: The authors certify that they have no commercial or associative interest that represents a conflict of interest in connection with the manuscript.

\section{Corresponding Author:}

Saeed Al Zahrani

E-mail: Saeedalzharani@gmail.com

hitps://doi.org/10.1590/1807-3107bor-2018.vol32.0057

Submitted: September 17, 2017

Accepted for publication: January 26, 2018

Last revision: May 10, 2018
Abstract: To evaluate peri-implant bone loss (PIBL) and stability around submerged and non-submerged dental implants in patients with and without type 2 diabetes mellitus (T2DM). Thirty-five T2DM and non-diabetic (NT2DM) patients were included in this study. Demographic data were recorded using a questionnaire and PIBL was measured on digital radiographs. Resonance frequency analysis (RFA) was carried out for each implant at the time of fixture placement and at 3 months in both groups. $P$ values less than 0.05 were considered statistically significant. One hundred and eighteen dental implants with a mean height of 10 to $12 \mathrm{~mm}$ and 3.3 to $4.1 \mathrm{~mm}$ in diameter were placed. The comparison of the mean RFA values at baseline and at 3 months was statistically significant $(p=0.008)$ in T2DM patients. The inter-group mean RFA values at baseline and at 3 months were not significant $(p>0.05)$. PIBL was significantly high in T2DM as compared to NT2DM patients at each follow-up ( $p<0.05)$. At 2, 3 , and 7 years, non-submerged dental implants showed significantly high PIBL in T2DM patients as compared to NT2DM individuals $(\mathrm{p}<0.05)$. The results of the present clinical study demonstrate increased PIBL around non-submerged single-tooth implant-supported restorations in T2DM patients, which may be due to the immune inflammatory status.

Keywords: Dental Implants; Diabetes Mellitus, Type 2; Resonance Frequency Analysis.

\section{Introduction}

Type 2 diabetes mellitus (T2DM) has been on the rise and has become a major public health problem. New estimates of T2DM among adults show a high disease burden, especially in developing countries. ${ }^{1}$ Recent data published by the World Health Organization (WHO) reveal an estimated 7 million adults have diabetes mellitus and more than 3 million Saudi Arabians are prediabetic. This is an alarming number as Saudi Arabia is ranked second in the Middle East and has the seventh highest rate of T2DM in the world. ${ }^{2}$ Patients with T2DM are associated with an increased risk of periodontal disease and tooth loss. ${ }^{3}$

Type 2 diabetes mellitus demands special attention in dental treatment, particularly when dental implants are to be placed. Interestingly, studies have 
reported that dental implant therapy is not restricted to systemically healthy individuals; T2DM patients are also potential candidates for dental implant therapy., However, the underlying pathophysiology that increases the risk of peri-implant tissue loss in subjects with T2DM cannot be disregarded. Research indicates that T2DM has been associated with the formation and accumulation of advanced glycation end products (AGEs), which contribute to its pathogenesis and to abnormal periodontal wound healing, ${ }^{6,7}$ These end products reduce the production of matrix proteins such as collagen and osteocalcin by gingival and periodontal fibroblasts. ${ }^{8}$ It has also been suggested that T2DM patients present with persistent inflammatory response, significant attachment loss, and increased alveolar bone resorption. ${ }^{9}$

There appears to be limited and controversial data available in the literature regarding peri-implant outcomes in patients with T2DM. Dental implant therapy was evaluated in T2DM patients in a 4-month prospective cohort study and revealed high clinical success. ${ }^{10}$ Similarly, results from a recent 24 -month study showed that dental implants can remain clinically and radiographically stable in T2DM patients in a manner that is similar to that observed in non-diabetic (NT2DM) individuals. ${ }^{11,12}$ However, these studies were conducted for a short follow-up period and, therefore, studies with a longer follow-up period may help to elucidate peri-implant outcomes and stability of dental implants in T2DM as compared to NT2DM patients. Thus, the aim of the present 7-year prospective observational study was to evaluate peri-implant bone loss (PIBL) and stability around submerged and non-submerged dental implants in T2DM and NT2DM patients.

\section{Methodology}

\section{Trial design and study setting}

The present study was performed in accordance with the Declaration of Helsinki revised in 2013 for experimentation involving human subjects. This was a 7-year prospective observational study which was designed, conducted, and reported following the 'Strengthening the Reporting of Observational Studies in Epidemiology' (STROBE) checklist. ${ }^{13}$ The clinical trial was conducted in King Abdulaziz Medical City, Dental Center, Riyadh, Saudi Arabia.
The study protocol was initially reviewed and later approved by the ethics committee of King Abdullah International Medical Research Center, Saudi Arabia.

\section{Inclusion and exclusion criteria}

Adult patients were recruited using the following criteria: a) diagnosis of T2DM (test group) and NT2DM (control group) according to the American Diabetes Association; ${ }^{14}$ b) $\mathrm{HbA1}$ c levels $>6.0 \%$ for T2DM patients and $\leq 6.0 \%$ for NT2DM patients at the time of surgery; ${ }^{10}$ c) single-tooth implant-supported restoration; c) adequate bone dimensions for implant placement without bone grafting; and e) implant sites with $\geq 3$ months of healing. Patients with any medical condition other than T2DM, such as acquired immune deficiency syndrome/HIV, cardiovascular disorders, and renal diseases, were excluded. In addition, patients with periodontal disease, former or current smoking status, and who had used medications such as steroids, nonsteroidal anti-inflammatory drugs, and antibiotics within the past 6 months were also excluded.

\section{Study participants}

Subjects were recruited from the National Guard community, Riyadh, Saudi Arabia from June 2009 to January 2011. Eligible participants were informed about the purpose and process of the study in the local language (Arabic) or in English, both verbally and in writing. A written informed consent was obtained. The study subjects signed a consent form and were allowed to withdraw from the research project at any time without any consequences.

\section{Questionnaire}

A trained interviewer collected information on gender, age, duration of diabetes, type of diabetes medication, previous complications from diabetes, and daily oral hygiene status of all study participants. Medical and dental histories were also recorded in a questionnaire sheet.

\section{Measurement of hemoglobin Alc levels}

HbA1c levels were measured in both T2DM and NT2DM patients using ion-exchange highperformance liquid chromatography (Adams A1c HA8160, Diabetes Mode, Arkray, Inc., Kyoto, Japan) and were expressed as percentages. 


\section{Surgical procedure}

A total of 118 dental implants (ITI $®$ Straumann Dental Implant System, Wandenburg, Switzerland) were placed in 70 patients (35 T2DM and 35 NT2DM patients) at the dental implant clinic between 2009 and 2011. All implants were placed according to the manufacturer's instructions. A traditional two-stage surgical protocol was used for submerged implant placement, whereas a one-stage surgical protocol was used for non-submerged implant placement. All surgical procedures were performed under local anesthesia. A crestal incision was made followed by elevation of a full-thickness mucoperiosteal flap. After the implant sites were prepared, all implants were placed using a torque controller. The mucosa was sutured after the implant placement. Some implants were placed with a submerged protocol and topped with a closure screw to avoid loading during the healing process, while some were placed with a non-submerged protocol, where the cover screw around the soft tissue was left exposed. The implants were left to heal for 3 months in the mandible and for 6 months in the maxilla until osseointegration was complete. Healing abutments were placed in the second stage. Final impressions were made, and the crowns were fabricated using traditional laboratory methods. After implant placement, radiographs were taken at the moment of prosthetic placement following standardized parameters to compare crestal bone levels at 1-year and 7-year follow up.

\section{Postoperative care}

After implant placement and suturing, each patient received $625 \mathrm{mg}$ of Augmentin and $400 \mathrm{mg}$ of Ibuprofen to be taken three times daily for 7 days, and a $0.2 \%$ chlorhexidine (Deef ${ }^{\circledR}$, AlQassim, Saudi Arabia) mouthwash was prescribed to all patients for 2 weeks. Patients were also asked to brush their teeth gently with antiseptic toothpaste. Sutures were removed 8-10 days after surgery. The patients were recalled at 1, 2, 3, and 7 years after implant placements. The criteria for successful implant placement were stable implants and superstructures with no symptoms of pain and without any signs of inflammation and purulent discharge, loss of no more than $1 \mathrm{~mm}$ bone around the implant in the first year, and no radiolucency around implants.

\section{Resonance frequency measurements}

Resonance frequency measurements were made for each implant at the time of fixture placement and at 3 months in both groups. The instrumentation used to perform the measurements had been previously described by Meredith et al. ${ }^{15}$ Measurements were carried out by screwing a transducer to the top of the abutment. The transducer beam comprised a small L-shaped cantilever to which two piezoceramic elements had been attached. One of the elements was excited by a sinewave signal of amplitude $1.0 \mathrm{v}$, whose frequency ranged from 6 to $12 \mathrm{kHz}$ in steps of $25 \mathrm{~Hz}$. The response of the beam was measured by the second piezoceramic element and the resonance frequency of the transducer/implant system was calculated from the peak amplitude of the signal.

\section{Peri-implant bone loss}

Peri-implant bone loss was defined as the distance from the widest supracrestal part of the implant to the alveolar crest. ${ }^{16}$ Digital intraoral radiographs were taken using the long-cone paralleling technique. To prepare parallel radiographs, a film holder (Dentsply Rinn, PA, USA) was used to standardize the angulation between the X-ray beam and the film. The central X-ray beam was directed perpendicularly to the film and long axis of the implant. At the implant sites, both mesial and distal PIBL were analyzed at 20x magnification using a computer software program (CorelDraw 11.0, Corel Corp and Coral Ltd, Ottawa, Canada).

\section{Statistical analysis}

Statistical analyses were carried out using the SPSS for Windows, v.20.0 (IBM, Chicago, IL, USA). Data were expressed as means and standard deviations. Normality of distribution of the variables was tested with Shapiro-Wilk tests and confirmed with Q-Q plots. For the purpose of analysis, the patients were split into subgroups according to diabetic status and position of fixture (submerged/non-submerged). PIBL was analyzed to identify any associations with T2DM and position of fixture and the time following implant placement $(1,2,3$, and 7 years). Betweengroup comparison of means was verified with the Mann-Whitney U test. The level of significance was set at 0.05 . 


\section{Results}

Out of 101 patients, 70 signed the informed consent form and participated in the study. The study groups consisted of 35 patients with T2DM (22 males and 13 females) and 35 NT2DM patients (24 males and 11 females) who were treated with dental implants (Figure). The mean age of T2DM and NT2DM patients was 54.6 years and 46.8 years, respectively. With regards to gender distribution, both groups showed a higher prevalence of men than of women. The mean duration of diabetes in T2DM patients was 12.6 years. Twice-daily toothbrushing was reported by $71 \%$ and $42 \%$ of NT2DM and T2DM patients, respectively (Table 1). None of the patients experienced allergy to penicillin medication.

A total of 118 dental implants with a mean height of 10 to $12 \mathrm{~mm}$ and 3.3 to $4.1 \mathrm{~mm}$ in diameter were placed. Sixty single-tooth implants were restored in the mandible while 58 single-tooth implants were placed

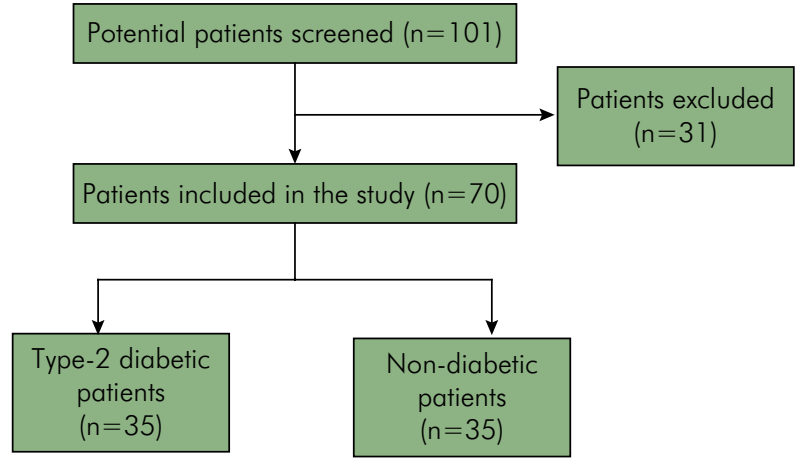

Figure. Study flow diagram showing recruitment details.

Table 1. Demographic characteristics of study participants.

\begin{tabular}{lcc}
\hline Characteristics & Non-diabetic & Type 2 diabetes \\
\hline Number of patients & 35 & 35 \\
Gender (M/F) & $24 / 11$ & $22 / 13$ \\
Mean age (years) & $46.8 \pm 8.1$ & $54.6 \pm 9.9$ \\
HbAlc levels (\%) & 4.7 & 8.2 \\
Duration of diabetes (years) & - & $12.6 \pm 1.7$ \\
Daily toothbrushing (\%) & & \\
Once & 29 & 58 \\
Twice & 71 & 42 \\
\hline
\end{tabular}

in the maxilla (Table 2). Of the 118 implants evaluated, 117 (99.15\%) survived for 7 years. One implant failure occurred at 6 months following implant placement in the T2DM group. This implant was successfully replaced and restored without further complications, and was evaluated at 1, 2, 3, and 7 years.

The comparison of the mean RFA values at baseline and at 3 months in T2DM patients was statistically significant $(p=0.008)$. The between-group mean RFA values at baseline and at 3 months was not significant $(\mathrm{p}>0.05)$ (Table 2).

Results for PIBL are shown in Table 3. PIBL was found to increase in both groups. However, there was a statistically significant difference between both groups in all follow-up periods. PIBL varied from $0.53 \mathrm{~mm}$ after the first year $(\mathrm{p}=0.004)$ to $1.1 \mathrm{~mm}$ after 7 years $(p=0.000)$ in T2DM patients (Table 3 ).

Table 4 shows PIBL between submerged and nonsubmerged dental implants at 1, 2, 3, and 7 years in T2DM and NT2DM patients. After the first year of assessment, there was a statistically significant difference for both submerged $(p=0.026)$ and nonsubmerged $(p=0.014)$ dental implants between T2DM and NT2DM groups. At 2, 3, and 7 years, only nonsubmerged dental implants showed significantly high PIBL in T2DM patients as compared to NT2DM individuals $(p<0.05)$ (Table 4).

\section{Discussion}

The aim of the present 7-year observational study was to evaluate PIBL and stability around submerged and non-submerged dental implants in T2DM and NT2DM patients. To our knowledge, this is the first study to evaluate PIBL and stability around submerged and non-submerged dental implants placed in T2DM and NT2DM patients. The findings of the present study showed that PIBL was significantly greater in T2DM as compared to NT2DM patients. Moreover, at 7 years, non-submerged dental implants showed more bone loss in T2DM than in NT2DM patients.

Replacing missing teeth with dental implants has been shown to be safe and effective, with a high success rate, despite certain factors that can influence the outcomes, including certain effects of T2DM on the osseointegration process in diabetic patients 
Table 2. Location, position, and stability of dental implants at baseline and at 3 months. Means of the resonance frequency analysis (RFA) are expressed in implant stability quotient (ISQ).

\begin{tabular}{|c|c|c|c|c|c|c|c|}
\hline \multirow[b]{2}{*}{ Groups } & \multicolumn{2}{|c|}{ Location of implants ( $n$ ) } & \multicolumn{2}{|c|}{ Position of fixture (n) } & \multicolumn{3}{|c|}{ RFA (ISQ) (mean \pm SD) } \\
\hline & Maxilla & Mandible & Submerged & Non-submerged & $\begin{array}{c}\text { Immediate } \\
\text { implant stability }\end{array}$ & $\begin{array}{l}\text { Implant stability } \\
\text { at } 3 \text { months }\end{array}$ & $p$-value \\
\hline Non-diabetic & 30 & 29 & 31 & 26 & $77.48 \pm 6.0$ & $79.75 \pm 5.5$ & 0.11 \\
\hline Type 2 diabetes & 28 & 31 & 29 & 32 & $75.79 \pm 6.6$ & $79.06 \pm 6.0$ & $0.008^{* * *}$ \\
\hline$p$-value & & & & & 0.31 & 0.64 & \\
\hline
\end{tabular}

${ }^{8}$ Between-group p-value; "Within-group p-value; ${ }^{* * *}$ Denotes statistically significant $\mathrm{p}$-value obtained by the Mann-Whitney $\mathrm{U}$ test.

Table 3. Peri-implant bone loss in T2DM and NT2DM at 1, 2, 3, and 7 years.

\begin{tabular}{lcccc}
\hline \multirow{2}{*}{ Groups } & \multicolumn{3}{c}{ PIBL $(\mathrm{mm})$} \\
\cline { 2 - 5 } & At 1 year & At 2 years & At 3 years & At 7 years \\
\hline Non-diabetic & $0.23 \pm 0.28$ & $0.33 \pm 0.46$ & $0.41 \pm 0.57$ & $0.58 \pm 0.70$ \\
Type 2 diabetes & $0.53 \pm 0.55$ & $0.74 \pm 0.62$ & $0.91 \pm 0.73$ & $1.1 \pm 0.81$ \\
p-value & $0.004^{*}$ & $0.004^{*}$ & $0.002^{*}$ & $0.00^{*}$ \\
\hline
\end{tabular}

*Denotes statistically significant $\mathrm{p}$-value obtained by the Mann-Whitney $\mathrm{U}$ test.

Table 4. Peri-implant bone loss in submerged and non-submerged dental implants at 1, 2, 3, and 7 years.

\begin{tabular}{|c|c|c|c|c|}
\hline \multirow{2}{*}{ Groups } & \multicolumn{4}{|c|}{$\mathrm{PIBL}(\mathrm{mm})$} \\
\hline & At 1 year & At 2 years & At 3 years & At 7 years \\
\hline \multicolumn{5}{|l|}{ Non-diabetic } \\
\hline Submerged implants & $0.22 \pm 0.36$ & $0.34 \pm 0.52$ & $0.41 \pm 0.71$ & $0.71 \pm 0.74$ \\
\hline Non-submerged implants & $0.28 \pm 0.17$ & $0.51 \pm 0.34$ & $0.62 \pm 0.31$ & $0.95 \pm 0.57$ \\
\hline \multicolumn{5}{|l|}{ Type 2 diabetes } \\
\hline Submerged implants & $0.33 \pm 0.36$ & $0.36 \pm 0.43$ & $0.44 \pm 0.62$ & $0.76 \pm 0.76$ \\
\hline Non-submerged implants & $0.34 \pm 0.50$ & $0.63 \pm 0.56$ & $0.82 \pm 0.63$ & $1.07 \pm 0.76$ \\
\hline \multicolumn{5}{|l|}{$p$-value } \\
\hline Submerged implants & 0.026 & 0.075 & 0.069 & 0.055 \\
\hline Non-submerged implants & 0.014 & 0.022 & 0.024 & 0.005 \\
\hline
\end{tabular}

P-values in boldface indicate statistical significance $(p<0.05)$ between both groups

who need dental implants. Some T2DM patients fail to control their glucose levels and maintain mean $\mathrm{HbA1c}$ values between $8.5 \%$ and $9 \% .{ }^{17}$ This study analyzed peri-implant marginal bone loss in diabetic and non-diabetic individuals. The findings of the present observational study concur with those of several earlier studies, which demonstrated that hyperglycemic state leads to alterations in bone functions. ${ }^{18,19,20,21}$ Other retrospective studies have also recognized pathological changes in bone function related to chronic hyperglycemia. ${ }^{22,23}$ The present study observed that PIBL was high in T2DM patients in relation to mean $\mathrm{HbA1c}$ levels of $8.2 \%$. These results corroborate those of previous clinical studies that showed increased alveolar bone loss among T2DM patients compared with non-diabetic individuals. ${ }^{24,25}$ This pathological mechanism can be explained by the increased serum levels of destructive proinflammatory cytokines (such as interleukin [IL]-1 $\beta$, IL-6, and tumor necrosis factor alpha [TNFa]) and of peri-implant crevicular fluid, as a result of the increased production of AGEs and impairment of the chemotactic and phagocytic functions of polymorphonuclear leukocytes in T2DM patients. ${ }^{26,27}$

High expression of proinflammatory cytokines has been observed in bone tissue, supporting the idea that the bone itself produces an inflammatory response in T2DM patients. ${ }^{28}$ Mechanisms of this type are likely 
to induce osteoclast formation and bone destruction, which may explain bone loss around implants of T2DM patients in the present study. ${ }^{29,30}$ However, increased bone resorption was statistically significant at $1,2,3$, and 7 years, a finding that is consistent with Morris et al. ${ }^{31}$ and Gómez-Moreno et al., ${ }^{32}$ whose T2DM patients showed high bone resorption rates during the progression of the disease according to the evaluation of implant survival rate or mean peri-implant bone level measured radiographically.

Interestingly, alveolar bone loss was observed around submerged and non-submerged implants in both groups. Clinically, however, the most important finding in this study was the significant osseous changes around nonsubmerged dental implants in T2DM and NT2DM patients. The exact mechanism that underlies periimplant bone changes around non-submerged dental implants is not known. However, several possibilities could explain these findings. One mechanism may involve bacterial colonization in the microgap and implant components. Evidence has been published which demonstrates the presence of bacteria in these areas under certain conditions. ${ }^{33,34}$ The epithelium could migrate beyond the microgap in an attempt to isolate the infection. This epithelial proliferation and subsequent physiological response to establish a biological width could be responsible for the approximately $1 \mathrm{~mm}$ of distance observed apically to the microgap. Moreover, another important factor that governs PIBL is daily oral care at home. Twice-daily toothbrushing was reported by $71 \%$ of NT2DM patients. However, only $42 \%$ of T2DM patients performed twice-daily toothbrushing. Therefore, plaque build-up as a result of low toothbrushing frequency may have contributed towards increased PIBL among T2DM patients.

The main strength of the present study is the study design and the follow-up period. No study has assessed PIBL around submerged and non-submerged dental implants in T2DM and NT2DM patients using a 7-year follow-up. Nevertheless, this study certainly has some limitations that should be taken into consideration when evaluating the present findings. First, there was no stratification of $\mathrm{HbA1c}$ levels among T2DM patients, and glucose levels were simply presented as a single mean value for all T2DM individuals. Furthermore, other peri-implant clinical parameters, such as peri-implant probing depth, should also have been assessed in order for PIBL to be deemed pathological. In addition, future observational studies should focus on the collection of peri-implant crevicular fluid to quantify the levels of cytokines at the sites of bone loss in T2DM patients. Moreover, cross-sectional studies should be performed for qualitative assessment of microbial plaque around dental implants in T2DM and NT2DM patients.

\section{Conclusion}

In conclusion, the results of the present 7-year follow-up clinical study demonstrated significant PIBL around non-submerged single-tooth implantsupported restorations in T2DM as compared to NT2DM patients, which may be explained by the immune inflammatory status of diabetic patients.

\section{Acknowledgements}

This project was funded by King Abdullah International Medical Research Center, Ministry of National Guard, Health Affairs, Riyadh, Saudi Arabia. The authors would like to thank Dr Ali Al Ehaideb, Chairman, Dental Services and Department of Dental Services, Central Region, King Abdulaziz Medical City, Ministry of National Guard Health Affairs, Riyadh, Saudi Arabia, for facilitating the conduction of the study.

\section{References}

1. Guariguata L, Whiting DR, Hambleton I, Beagley J, Linnenkamp U, Shaw JE. Global estimates of diabetes prevalence for 2013 and projections for 2035. Diabetes Res Clin Pract. 2014 Feb;103(2):137-49. https://doi.org/10.1016/i.diabres.2013.11.002
2. Robert AA, Al Dawish MA, Braham R, Musallam MA, Al Hayek AA, Al Kahtany NH. Type 2 diabetes mellitus in Saudi Arabia: major challenges and possible solutions. Curr Diabetes Rev. 2017;13(1):59-64. https://doi.org/10.2174/1573399812666160126142605 
3. Almas K, Al-Qahtani M, Al-Yami M, Khan N. The relationship between periodontal disease and blood glucose level among type II diabetic patients. J Contemp Dent Pract. 2001 Nov;2(4):18-25.

4. Aguilar-Salvatierra A, Calvo-Guirado JL, González-Jaranay M, Moreu G, Delgado-Ruiz RA, Gómez-Moreno G. Periimplant evaluation of immediately loaded implants placed in esthetic zone in patients with diabetes mellitus type 2: a twoyear study. Clin Oral Implants Res. 2016 Feb;27(2):156-61. https://doi.org/10.1111/clr.12552

5. Naujokat $H$, Kunzendorf B, Wiltfang J. Dental implants and diabetes mellitus-a systematic review. Int J Implant Dent. 2016 Dec;2(1):5. https://doi.org/10.1186/s40729-016-0038-2

6. Singhal S, Pradeep AR, Kanoriya D, Garg V. Human soluble receptor for advanced glycation end products and tumor necrosis factor- $\alpha$ as gingival crevicular fluid and serum markers of inflammation in chronic periodontitis and type 2 diabetes. J Oral Sci. 2016;58(4):547-53. https://doi.org/10.2334/josnusd.16-0017

7. Chang PC, Chien LY, Yeo JF, Wang YP, Chung MC, Chong $\mathrm{LY}$ et al. Progression of periodontal destruction and the roles of advanced glycation end products in experimental diabetes. J Periodontol. 2013 Mar;84(3):379-88. https://doi.org/10.1902/jop.2012.120076

8. Alikhani M, Alikhani Z, Boyd C, MacLellan CM, Raptis $M$, Liu R et al. Advanced glycation end products stimulate osteoblast apoptosis via the MAP kinase and cytosolic apoptotic pathways. Bone. 2007 Feb;40(2):345-53. https://doi.org/10.1016/i.bone.2006.09.011

9. Liu R, Bal HS, Desta T, Krothapalli N, Alyassi M, Luan Q et al. Diabetes enhances periodontal bone loss through enhanced resorption and diminished bone formation. J Dent Res. 2006 Jun;85(6):510-4. https://doi.org/10.1177/154405910608500606

10. Dowell S, Oates TW, Robinson M. Implant success in people with type 2 diabetes mellitus with varying glycemic control: a pilot study. J Am Dent Assoc. 2007 Mar;138(3):355-61. https://doi.org/10.14219/jada.archive.2007.0168

11. Abduljabbar T, Al-Sahaly F, Al-Kathami M, Afzal $S$, Vohra F. Comparison of periodontal and periimplant inflammatory parameters among patients with prediabetes, type 2 diabetes mellitus and non-diabetic controls. Acta Odontol Scand. 2017 Jul;75(5):319-24. https://doi.org/10.1080/00016357.2017.1303848

12. Al Amri MD, Abduljabbar TS, Al-Kheraif AA, Romanos $\mathrm{GE}$, Javed F. Comparison of clinical and radiographic status around dental implants placed in patients with and without prediabetes: 1-year follow-up outcomes. Clin Oral Implants Res. 2017 Feb;28(2):231-5. https://doi.org/10.1111/clr.12788 PMID:26804207

13. von Elm E, Altman DG, Egger M, Pocock SJ, Gøtzsche PC, Vandenbroucke JP. The Strengthening the Reporting of Observational Studies in Epidemiology (STROBE) statement: guidelines for reporting observational studies. Int J Surg. 2014 Dec;12(12):1495-9. https://doi.org/10.1016/i.ijsu.2014.07.013
14. American Diabetes Association. Diagnosis and classification of diabetes mellitus. Diabetes Care. 2006 Jan;29 Suppl 1:S43-8. https://doi.org/10.2337/dc10-S062

15. Meredith N, Book K, Friberg B, Jemt T, Sennerby L. Resonance frequency measurements of implant stability in vivo: a crosssectional and longitudinal study of resonance frequency measurements on implants in the edentulous and partially dentate maxilla. Clin Oral Implants Res. 1997 Jun;8(3):22633. https://doi.org/10.1034/j.1600-0501.1997.080309.x

16. García-García M, Mir-Mari J, Benic GI, Figueiredo R, Valmaseda-Castellón E. Accuracy of periapical radiography in assessing bone level in implants affected by peri-implantitis: a cross-sectional study. J Clin Periodontol. 2016;43(1):85-91. https://doi.org/10.1111/jcpe.12491

17. Kirk JK, Bell RA, Bertoni AG, Arcury TA, Quandt SA, Goff DC Jr et al. Ethnic disparities: control of glycemia, blood pressure, and LDL cholesterol among US adults with type 2 diabetes. Ann Pharmacother. 2005 Sep;39(9):1489-501. https://doi.org/10.1345/aph.1E685

18. Wu YY, Xiao E, Graves DT. Diabetes mellitus related bone metabolism and periodontal disease. Int J Oral Sci. 2015 Jun;7(2):63-72. https://doi.org/10.1038/ijos.2015.2

19. Oates TW Jr, Galloway P, Alexander P, Vargas Green A, Huynh$\mathrm{Ba} G$, Feine J et al. The effects of elevated hemoglobin A(1c) in patients with type 2 diabetes mellitus on dental implants: survival and stability at one year. J Am Dent Assoc. 2014 Dec;145(12):1218-26. https://doi.org/10.14219/jada.2014.93

20. Conte A, Ghiraldini B, Casarin RC, Casati MZ, Pimentel SP, Cirano FR et al. Impact of type 2 diabetes on the gene expression of bone-related factors at sites receiving dental implants. Int J Oral Maxillofac Surg. 2015 Oct;44(10):13028. https://doi.org/10.1016/j.ijom.2015.06.001

21. de Molon RS, Morais-Camilo JA, Verzola MH, Faeda RS, Pepato MT, Marcantonio E Jr. Impact of diabetes mellitus and metabolic control on bone healing around osseointegrated implants: removal torque and histomorphometric analysis in rats. Clin Oral Implants Res. 2013 Jul;24(7):831-7. https://doi.org/10.1111/j.1600-0501.2012.02467.x

22. He J, Zhao B, Deng C, Shang D, Zhang C. Assessment of implant cumulative survival rates in sites with different bone density and related prognostic factors: an 8 -year retrospective study of 2,684 implants. Int J Oral Maxillofac Implants. 2015 Mar-Apr;30(2):360-71. https://doi.org/10.11607/jomi.3580

23. Anner R, Grossmann Y, Anner Y, Levin L. Smoking, diabetes mellitus, periodontitis, and supportive periodontal treatment as factors associated with dental implant survival: a long-term retrospective evaluation of patients followed for up to 10 years. Implant Dent. 2010 Feb;19(1):57-64. https://doi.org/10.1097/ID.0b013e3181bb8f6c

24. Javed F, Näsström K, Benchimol D, Altamash M, Klinge B, Engström PE. Comparison of periodontal and socioeconomic status between subjects with type 2 diabetes mellitus and non-diabetic controls. J Periodontol. 2007 Nov;78(11):2112-9. https://doi.org/10.1902/jop.2007.070186 
Stability and bone loss around submerged and non-submerged implants in diabetic and non-diabetic patients: a 7-year follow-up

25. Javed F, Al-Kheraif AA, Salazar-Lazo K, Yanez-Fontenla V, Aldosary KM, Alshehri M et al. Periodontal inflammatory conditions among smokers and never-smokers with and without type 2 diabetes mellitus. J Periodontol. 2015 Jul;86(7):839-46. https://doi.org/10.1902/jop.2015.150120

26. Takeda M, Ojima M, Yoshioka H, Inaba H, Kogo M, Shizukuishi $S$ et al. Relationship of serum advanced glycation end products with deterioration of periodontitis in type 2 diabetes patients. J Periodontol. 2006 Jan;77(1):15-20. https://doi.org/10.1902/jop.2006.77.1.15

27. Akram Z, Abduliabbar T, Abu Hassan MI, Javed F, Vohra F. Cytokine profile in chronic periodontitis patients with and without obesity: a systematic review and meta-analysis. Dis Markers. 2016;2016:4801418. https://doi.org/10.1155/2016/4801418

28. Morais JA, Trindade-Suedam IK, Pepato MT, Marcantonio Junior E, Wenzel A, Scaf G. Effect of diabetes mellitus and insulin therapy on bone density around osseointegrated dental implants: a digital subtraction radiography study in rats. Clin Oral Implants Res. 2009 Aug;20(8):796-801. https://doi.org/10.1111/j.1600-0501.2009.01716.x
29. Javed F, Romanos GE. Impact of diabetes mellitus and glycemic control on the osseointegration of dental implants: a systematic literature review. J Periodontol. 2009 Nov;80(11):1719-30. https://doi.org/10.1902/jop.2009.090283

30. Graves DT, Liu R, Oates TW. Diabetes-enhanced inflammation and apoptosis: impact on periodontal pathosis. Periodontol 2000. 2007;45(1):128-37. https://doi.org/10.1111/j.1600-0757.2007.00219.x

31. Morris HF, Ochi S, Winkler S. Implant survival in patients with type 2 diabetes: placement to 36 months. Ann Periodontol. 2000 Dec;5(1):157-65. https://doi.org/10.1902/annals.2000.5.1.157

32. Gómez-Moreno G, Aguilar-Salvatierra A, Rubio Roldán J, Guardia J, Gargallo J, Calvo-Guirado JL. Peri-implant evaluation in type 2 diabetes mellitus patients: a 3-year study. Clin Oral Implants Res. 2015;26(9):1031-5. https://doi.org/10.1111/clr.12391

33. Dibart S, Warbington M, Su MF, Skobe Z. In vitro evaluation of the implant-abutment bacterial seal: the locking taper system. Int J Oral Maxillofac Implants. 2005 Sep-Oct;20(5):732-7.

34. Persson LG, Lekholm U. Leonhardt $\AA$, Dahlen G, Lindhe J. Bacterial colonization on internal surfaces of Brå nemark system ${ }^{\circledR}$ implant components. Clin Oral Implants Res. 1996;7(2):90-5. https://doi.org/10.1034/i.1600-0501.1996.070201.x 